\title{
Students' Responses to Professionally Contextualized Activities in a Studio Class
}

\author{
Mr. Ayman M. Alabdullatif, Oregon State University \\ Mr. Shane Paul Lorona, Oregon State University \\ Dr. Milo Koretsky, Oregon State University
}

Milo Koretsky is a Professor of Chemical Engineering at Oregon State University. He received his B.S. and M.S. degrees from UC San Diego and his Ph.D. from UC Berkeley, all in Chemical Engineering. He currently has research activity in areas related engineering education and is interested in integrating technology into effective educational practices and in promoting the use of higher-level cognitive skills in engineering problem solving. His research interests particularly focus on what prevents students from being able to integrate and extend the knowledge developed in specific courses in the core curriculum to the more complex, authentic problems and projects they face as professionals. Dr. Koretsky is one of the founding members of the Center for Lifelong STEM Education Research at OSU. 


\section{Students' Responses to Professionally Contextualized Activities in a Studio Class}

\section{Introduction}

In a project to "re-situate” learning to better align student work at school with the work they will do in professional practice, the School of Chemical, Biological, and Environmental Engineering at Oregon State University is implementing a new activity design in its studio classes [1]. Ten core courses (e.g., material and energy balances, thermodynamics, transport, and chemical reaction engineering) have incorporated weekly studios into the instructional architecture. In studios, students work together in mostly 3-person groups, facilitated by trained graduate student teaching assistants (GTAs), undergraduate learning assistants (LAs), and the course instructor. Studios are designed to extend students' thinking and problem-solving techniques while simultaneously reinforcing core content and developing teamwork and communication skills [2].

In its original design, Studio 1.0, student activity often relied on sequestered, worksheet-based problems. These problems helped students identify and practice key conceptual and procedural knowledge, and connect that understanding to lecture. As educators, we have become concerned that the nature of the Studio 1.0 activities limited both students' ability to connect their work to professional practice and to develop value systems corresponding to the engineering profession. In response, we have created a revised design, Studio 2.0. Studio 2.0 incorporates more authentic and open-ended activities that focus on contextualizing work in engineering practice. An important aspect of the activity design is to create the need for students to use their engineering judgment to make decisions.

It is our assertion that by shifting activity to provide groups more realistic work and greater authorship of possible solutions will have several benefits. This change will facilitate the transfer of what they learn in one course to other courses and ultimately to practice. It will also help them become more creative problem solvers, and more fully develop students' engineering identity.

This research study represents a first step towards evaluating these lofty goals by examining how students take up these new studio activities. Using Engle's idea of framing for transfer [3], we compare the ways that students respond about their own learning in a set of five re-designed Studio 2.0 activities to their responses to four activities that remained the original Studio 1.0 version. The data were collected in the same course where the student's worked in designated teams with the same studio instructors throughout the term. Specifically, we ask the following research questions:

1. How do students' self-reports of the effectiveness on their learning compare between Studio 1.0 and 2.0?

2. Do student free-response descriptions about what they learned in Studio 2.0 activities differ from Studio 1.0? Do the differences align with the intent of the re-design? 


\section{Conceptual Framework}

We connect the activity design in Studio 2.0 to student learning through the concepts of transfer, framing, and free and forced moves in problem solving. Transfer is the process in which learning to participate in an activity in one situation influences (positively or negatively) one's ability to participate in another activity in a different situation [4]. For example, it is desirable for engineers to be able to transfer knowledge and skills learned from classroom activity to the project work they will face in engineering practice. Researchers have pointed both to the depth to which content is learned [5] and the context in which the learning takes place [6] as critical for transfer.

Framing is a meta-communicative act of characterizing what is happening in a given context [3]. For example, an instructor can frame a learning from an activity as something that the students need to learn so that they can do well on an exam, or as a tool that they can use for future problems they are likely to face in their professional life. The first is an example of bounded framing, and the second example is of expansive framing. In a similar way that an instructor's classroom interactions can frame learning, activity design is an important element of context, as well, and can suggest more bounded or expansive frames.

Expansive framing has shown to promote transfer [3]. In expansive framing roles, learners are positioned as active participants in a learning context where they serve as authors of their own ideas and respondents to the ideas of others. This process aligns with the notion of free and forced moves in engineering practice [7]. In free moves, students have authorship to come up with their own approach to solve a problem. Once the approach is selected, it is followed by a set of forced moves where the students are expected to conform to disciplinary norms and practices and follow a specific path to get a "final answer." Unfortunately, in engineering science classes, the instructor provides authorship and students are only expected to conform to the disciplinary norms and practices mandated by forced moves. Our premise in Studio 2.0 design is that by providing activity in a context that gives students authorship through free moves, it is expansively framed. This research study seeks to characterize students' descriptions of their own learning and see if it is consistent with this hypothesis.

\section{Methods}

This study is part of a larger effort to resituate learning in a large land-grant university to move from decontextualized to more realistic activities. It looks at two instructional design approaches, Studio 1.0 and Studio 2.0, in the same course. Since the students interact with the same set of instructors and with the same group members (only changing group composition at mid-term) in the same classroom setting, the context for instruction is relatively stable. This design allows us to focus on how activity design frames a context for transfer. We collect both Likert-scale and free response data from students about each of their studio experiences. While the Likert data represents a self-report, we argue that what student's articulate that they learned is more than perception of learning, but rather a meta-measure of learning itself. 


\section{Participants}

The study was conducted is a sophomore level studio class serving chemical, biological, and environmental engineering students. This is a sophomore level course, but there were also junior and senior students registered. Over the term, students attended 9 weekly studio sessions of which five used the redesigned pedagogy. They were placed in teams of mostly three students with the remaining teams having two students. Team composition was changed once at the midpoint of the term. The instructors for the course and each studio section remained the same throughout the term. Two-hundred and twenty four students participated. The study was approved by the Institutional Review Board and students consented to participation.

\section{Studio design}

Table 1 describes the elements of the designs of the original Studio 1.0 and the re-designed Studio 2.0. Studio 1.0 activity almost exclusively elicits forced moves where learners are directed to follow a specific path to complete the studio activity. In contrast, Studio 2.0 activity is designed to provide learners with authorship of free moves. The studio model is described in detail in ref [2] and examples of Studio 1.0 and 2.0 and Instructional Design Principles for Studio 2.0 are presented in ref [1].

Table 1. A comparison between studio designs. A brief description is given for each design.

\begin{tabular}{|l|l|l|l|}
\hline $\begin{array}{l}\text { Studio } \\
\text { design }\end{array}$ & Framing & Moves involved & Description \\
\hline Studio 1.0 & $\begin{array}{l}\text { More bounded } \\
\text { framing }\end{array}$ & $\begin{array}{l}\text { Mostly forced } \\
\text { moves }\end{array}$ & $\begin{array}{l}\text { The activities in this design force the learners to follow a } \\
\text { specific path to get to a "final answer" that is either right or } \\
\text { wrong. Learners do not have the chance to express their } \\
\text { creativity and problem solving skills. }\end{array}$ \\
\hline Studio 2.0 & $\begin{array}{l}\text { More } \\
\text { expansive } \\
\text { framing }\end{array}$ & $\begin{array}{l}\text { Free and forced } \\
\text { moves }\end{array}$ & $\begin{array}{l}\text { The activities in this design are more open ended. The } \\
\text { learners are presented with a problem that is professionally } \\
\text { contextualized. They are not forced to follow a specific } \\
\text { path, rather they are encouraged to work with their group } \\
\text { to come up with their own path and deduce a reasonable } \\
\text { answer on their own. }\end{array}$ \\
\hline
\end{tabular}

\section{Data}

A survey was delivered three times during the term that specifically asked students about their learning in each of nine studio activities; four were Studio 1.0 versions while five were Studio 2.0. We asked students to respond to two items: (1) write down one thing that you learned from the studio activity [free response]; (2) the studio activity helped you learn the course content [Likert scale $(1=$ strongly disagree to $5=$ strongly agree)]. A total of 1865 responses were received for each item. The Likert scale questions were quantitatively analyzed and an emergent coding process was used to analyze the free response question, described next. While the Likert responses are clearly self-reports, the free response question that was asked before was designed to focus student thinking about a specific studio activity. Moreover, by having a student identify and articulate what she or he learned, they need to recall content which may be contextualized. In this vein, we can view these statements as a measure of learning as much as a self-report. 


\section{Coding}

The coding process involved multiple iterations until the final coding scheme was developed. Table 2 shows the two coding categories that emerged: application of learning and context. Application of learning is described as either task-specific or more general to engineering practice. Context refers to whether students identified the engineering context addressed in the activity. Once the coding scheme was established, it was independently applied to Studio 1.0 by two researchers. A Cohen's kappa value of 0.76 was achieved suggesting a suitably reliable coding scheme.

Table 2. Coding scheme that was used in evaluating the responses. For each coding category, the operational definition and example responses were given.

\begin{tabular}{|c|c|c|c|}
\hline $\begin{array}{l}\text { Code } \\
\text { Category }\end{array}$ & Label & Operational definition & Example responses \\
\hline \multirow[b]{2}{*}{$\begin{array}{l}\text { Application } \\
\text { of learning }\end{array}$} & Isolated & $\begin{array}{l}\text { Students stated that } \\
\text { they learned something } \\
\text { that was specifically } \\
\text { stated as an outcome of } \\
\text { the studio. This } \\
\text { included generic } \\
\text { concepts that are not } \\
\text { followed by how they } \\
\text { can be applied to other } \\
\text { problems. }\end{array}$ & $\begin{array}{l}\text { "I learned how to do linear regression and better } \\
\text { understood how to do that week's homework more } \\
\text { quickly.” (Studio 5, Student 107) } \\
\text { “That was really beneficial because it helped me with the } \\
\text { homework.” (Studio 5, Student 131) }\end{array}$ \\
\hline & Integrated & $\begin{array}{l}\text { Students stated that } \\
\text { they learned something } \\
\text { that was relevant to } \\
\text { engineering practice } \\
\text { but went beyond what } \\
\text { was specifically stated } \\
\text { as an outcome of the } \\
\text { studio, or the means to } \\
\text { get these outcomes. }\end{array}$ & $\begin{array}{l}\text { "I learned that there isn't always a right answer. In fact, in } \\
\text { many cases there are no right or wrong answers. } \\
\text { However, you MUST be able to provide an answer with } \\
\text { sufficient evidence and support. I think that this studio } \\
\text { helped me realize that the real world isn't perfect after } \\
\text { school, and that trouble shooting and problem solving are } \\
\text { more important than a plug and chug mentality." (Studio } \\
\text { 9, Student 66) } \\
\text { "I learned that there are real world application of the } \\
\text { things we are learning in class. In reality, almost } \\
\text { everything is variable, especially in engineering. That } \\
\text { studio, along with the analysis we did in class today, } \\
\text { really changed my thinking on the professional aspect to } \\
\text { everything and how things work in real life." (Studio 6, } \\
\text { Student 94) }\end{array}$ \\
\hline Contextual & & $\begin{array}{l}\text { Students mentioned } \\
\text { something that is } \\
\text { specific to the context } \\
\text { of the studio. }\end{array}$ & $\begin{array}{l}\text { "I learned about how hydraulic fracturing works, and } \\
\text { how it effects the environment.” (Studio 1, Student 90) } \\
\text { "Using kinematics along with excel you can solve for the } \\
\text { time necessary for a process to complete to a satisfactory } \\
\text { degree. (ie. } 70 \% \text { of a chemical converted)" (Studio 6, } \\
\text { Student 217) }\end{array}$ \\
\hline No learning & & $\begin{array}{l}\text { Students did not } \\
\text { identify any learning } \\
\text { outcome in the survey. }\end{array}$ & $\begin{array}{l}\text { "hmm i dont really remember this one all too well” } \\
\text { (Studio 8, Student 165) } \\
\text { “Not much. It was a repeat of the homework” (Studio 3, } \\
\text { Student 157) }\end{array}$ \\
\hline
\end{tabular}




\section{Results}

\section{Likert responses analysis}

Table 3 shows Likert responses for each of nine studio activities as well as their averages (Avg) and standard deviations (StD). The studios are numbered chronologically with the five new Studio 2.0 activities shown in the first rows of the table and the older Studio 1.0 activities shown in the latter four rows. There was no significant difference in ratings of learning between the Studio 1.0 and 2.0 approaches. However, further analyses of open ended responses suggested students saw the work differently in Studio 2.0. Many responses indicate that students connected Studio 2.0 activities with real-world engineering. For example, one student wrote, "I had such a great time in studio this morning. I feel like a real chemical engineer for once. I'm proud of my new ability to attack these problems by using my math skills and intuition. I love solving these kinds of problems and am excited for my future.” While students perceived both Studio 1.0 and 2.0 designs as effective, this type of response led us to characterize the free response item to see if there were differences in what students identified in their own learning.

Table 3. Likert responses if students believed the studio activity helped them learn the course content. ( 1 = strongly disagree; 2 = disagree; 3 = neutral; 4 = agree; 5 = strongly agree). Studio 1.0 below the dotted line, 2.0 above.

\begin{tabular}{lclrrrrrrrr}
\hline Likert & Design & Activity & $\mathbf{1}$ & $\mathbf{2}$ & $\mathbf{3}$ & $\mathbf{4}$ & $\mathbf{5}$ & $\mathbf{n}$ & Avg & StD \\
\hline Studio 1 & 2.0 & Hydraulic Fracturing & 3 & 14 & 56 & 116 & 24 & 213 & 3.68 & 0.66 \\
Studio 6 & 2.0 & Sucrose Kinetics: Regression & 4 & 8 & 41 & 111 & 60 & 224 & 3.96 & 0.76 \\
Studio 7 & 2.0 & Potato Chip Bag Sealer: ANOVA & 5 & 4 & 27 & 102 & 55 & 193 & 4.03 & 0.74 \\
Studio 8 & 2.0 & Sucrose Batch: SPC & 3 & 3 & 46 & 96 & 45 & 193 & 3.92 & 0.67 \\
Studio 9 & 2.0 & DOE: VCVD-_-_-_-_-_-_-_-_5 & -11 & 27 & -76 & 72 & 191 & 4.04 & 0.99 \\
\hline Studio 2 & 1.0 & Coin flips (samples/populations) & 4 & 15 & 42 & 116 & 39 & 216 & 3.79 & 0.78 \\
Studio 3 & 1.0 & Monte Carlo (Sampling Dist) & 3 & 15 & 40 & 97 & 57 & 212 & 3.90 & 0.86 \\
Studio 4 & 1.0 & Conceptual / MATLAB & 5 & 10 & 28 & 117 & 40 & 200 & 3.89 & 0.76 \\
Studio 5 & 1.0 & Conceptual & 8 & 6 & 33 & 121 & 51 & 219 & 3.92 & 0.82 \\
\hline
\end{tabular}

Free responses analysis

A correspondence analysis was performed on the coded responses to test if there are any statistically significant differences between the studios. In this analysis, each individual studio was considered separately. Table 4 shows a two-way contingency table and provides the number of responses in each category for each studio. Studios 1 and 6 of the Studio 2.0 design stand out as having more integrated responses and more contextual responses; differences between Studios 7, 8, and 9 and the four Studio 1.0 activities are not so clear. To investigate further, we performed a chi-square test on the entire data and also on clusters of sub-groups of studios. 
Table 4. A contingency table that relates studio with the coding category. The numbers represent the frequency of responses for each code category.

\begin{tabular}{|c|c|c|c|c|c|c|c|}
\hline $\begin{array}{l}\text { Free } \\
\text { Response }\end{array}$ & Design & $\begin{array}{c}\text { Integrated } \\
\text { and } \\
\text { contextual } \\
\end{array}$ & $\begin{array}{c}\text { Integrated } \\
\text { and not } \\
\text { contextual } \\
\end{array}$ & $\begin{array}{c}\text { Isolated } \\
\text { and } \\
\text { contextual } \\
\end{array}$ & $\begin{array}{c}\text { Isolated and } \\
\text { not } \\
\text { contextual } \\
\end{array}$ & $\begin{array}{c}\text { No } \\
\text { learning }\end{array}$ & Total \\
\hline Studio 1 & 2.0 & 15 & 59 & 12 & 98 & 22 & 206 \\
\hline Studio 6 & 2.0 & 26 & 97 & 35 & 38 & 24 & 220 \\
\hline Studio 7 & 2.0 & 2 & 57 & 4 & 117 & 18 & 198 \\
\hline Studio 8 & 2.0 & 6 & 40 & 2 & 106 & 40 & 194 \\
\hline Studio 9 & 2.0 & 4 & 60 & 2 & 96 & 34 & 196 \\
\hline Studio 2 & 1.0 & 0 & 36 & 0 & 134 & 37 & 207 \\
\hline Studio 3 & 1.0 & 3 & 42 & 5 & 122 & 34 & 206 \\
\hline Studio 4 & 1.0 & 1 & 69 & 1 & 120 & 28 & 219 \\
\hline Studio 5 & 1.0 & 0 & 65 & 0 & 123 & 31 & 219 \\
\hline
\end{tabular}

A chi-square test was performed in which the test statistic $t$ is calculated and compared to a critical chi-square value using a 95\% confidence level. If $t$ is smaller than the critical chi-square value, then the two categories tested are independent. In other words, if $t$ is smaller, then the tested studios cannot be said to come from different populations but rather that the difference in score may be due to chance. We expected to see sub-groups forming based on studio design with Studio 2.0 design to be clustered in a sub-group together, and Studio 1.0 design to be in a different sub-group.

Table 5 shows the results of this analysis. Looking at the entire data set (first row), we can say with high confidence that not all the studios belong to the same population. However, some sets of studios formed sub-groups where students responded similarly. Statistically, there is no evidence to say that the responses from any of these studios was from a different population. The subgroups include Studios 4, 5, 7, and 9, which includes two Studio 1.0 and two Studio 2.0 designs, and Studios 2, 3, and 8 which includes two Studio 1.0 and one Studio 2.0 designs. The two studios that are clearly independent (Studio 1 and Studio 6) were both Studio 2.0 designs. The results of the analysis shown in Table 5 shows that, by this measure, unlike Studios 1 and 6, Studio 2.0 designs in 7, 8, and 9 did not have striking differences from the Studio 1.0 design.

Table 5. The results of correspondence analysis performed for different groups of studios. The critical Chi-square value is based on the corresponding degrees of freedom and a 95\% confidence level.

\begin{tabular}{|c|c|c|c|c|}
\hline \multicolumn{2}{|c|}{ Sub-Group } & Test Statistic $t$ & $\begin{array}{c}\text { Critical Chi-square } \\
\text { Value }\end{array}$ & Sub-groups \\
\hline \multicolumn{2}{|c|}{ Entire data set } & 348.3 & 46.19 & $\begin{array}{c}\text { Statistical } \\
\text { differences }\end{array}$ \\
\hline Group 1 & Studio 6 & - & - & - \\
\hline Group 2 & Studio 1 & - & - & - \\
\hline Group 3 & Studios $4,5,7$, and 9 & 18.65 & 21.03 & Independent \\
\hline Group 4 & Studios 2, 3, and 8 & 15.13 & 15.51 & Independent \\
\hline
\end{tabular}


Figure 1 shows a plot of the integrated responses in relation to the contextual responses. The subgroups from Table 5 are identified with different colors and the studio design by different shapes (circle for Studio 1.0 and triangle for Studio 2.0). The frequency of the responses showed a positive correlation coefficient of +0.87 .

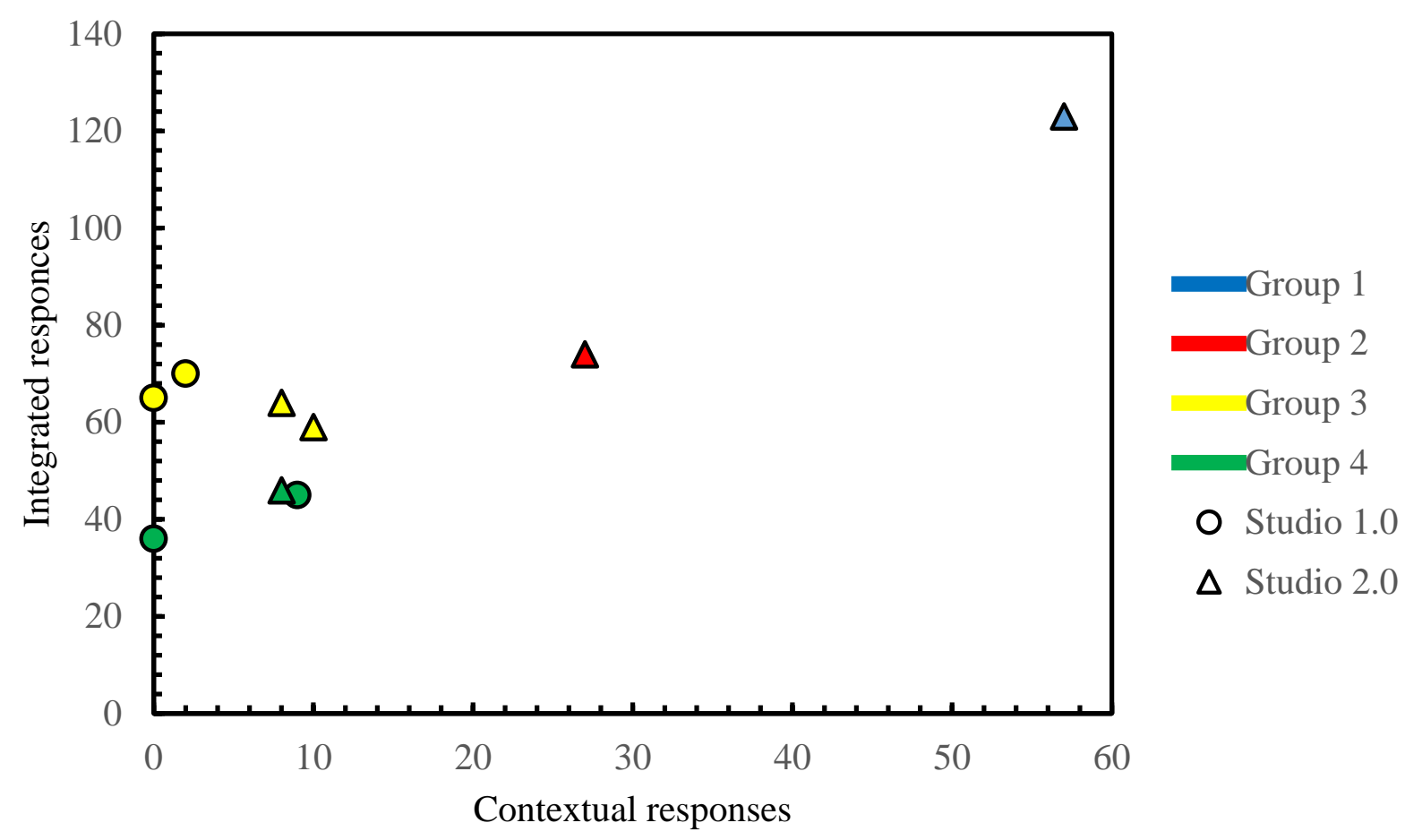

Figure 1. Scatter plot of the relationship between contextual responses and integrated responses. Each sub-group from Table 4 is plotted as a different color. Studio 1.0 is shown in circles and Studio 2.0 is shown in triangles.

\section{Discussion}

\section{Likert responses}

The results from the Likert items indicate that both Studio 1.0 and Studio 2.0 designs are perceived to be effective. To a degree, the perceived success and satisfaction of Studio 1.0 makes change to Studio 2.0 more challenging and perhaps difficult to justify (both for students and for faculty). The emerging theory from the larger change project [1] suggests that engineering pedagogical and curricular norms derive, in part, from the norms of university STEM education practices. Most current faculty were themselves highly successful in an environment emphasizing sequestered activities. These experiences can lead to a set of ongoing practices (e.g., isolated contexts, lack of opportunities for students to examine professional cultures and their practices, tenure and promotion practices) that serve to re-establish these norms in the face of curricular and pedagogical innovation. Students, too, can be complicit in re-establishing these norms when they seek to "game" the system by sharing experiences and work products in ways that are not centered on integration and expansion of ideas, but rather on getting desired grades. Thus, we were encouraged by the student's free responses. 


\section{Free responses}

We argue that being able to identify and articulate what is learned is more than a perception of learning but rather a form of meta-knowledge that is an indicator of how ready students will be to transfer what they learn in the classroom to professional contexts. The correspondence analysis (Table 4) showed that on average, Studio 2.0 design received 26\% more integrated responses compared to Studio 1.0. In addition, as shown in Figure 1, there appears to be a relation between contextualizing work and students' ability to integrate, i.e., a correlation coefficient of +0.86 between integrated responses and contextual responses. We might infer that the more memorable and realistic the context of the studio is, the more integrated responses are observed. This assertion is consistent with other educational research studies [8].

While, on average, the Studio 2.0 design provided more integrated and contextual responses, not all studios performed equivalently. There is a clear distinction between Studios 1 and 6, and Studios 7, 8, and 9 as shown in Table 5. The latter ones were statistically equivalent to other Studio 1.0 design in their own sub-groups. This result suggests that there are certain aspects of Studio 2.0 design were captured in Studios 1 and 6 to a greater extent than in the others, but analysis of other data sources would be useful to verify this conjecture.

The next step in the project is content analysis and video analysis to identify the features that make some studios more effective by this measure than others. There is a need to consider enculturation. While Studio 1 provided encouraging results from the free response analysis, it rated the lowest from the Likert scale. We speculate that students were negotiating the openendedness of the Studio 2.0 design and some may have been uncomfortable by the need to author free moves. With time, we would expect this discomfort to diminish.

\section{Conclusion}

The results from this research study provide a piece of evidence that the curricular change of Studio 2.0 is aligned with the project's goal of better preparing students for practice. Some studios elicited many more integrated and contextual responses even when compared to others from the same design. Research is needed to better understand the aspects that elicit these responses.

The study described here enabled a relatively quick measure into studio activity and is being complemented by more extensive video investigation of students' interactions with the different studio designs [9]. Importantly, we are also working to cultivate shared faculty understanding of the Studio 2.0 design [1].

The results provide more general support for the notion that contextualized activity provides more expansive framing for transfer [3]. We recommend that instructors frame the activity in their classroom (e.g., examples, group problems, and homework) in ways that help students better connect their work to that of professional practice. Such framing can be included both in the problem statement itself, and in how it is communicated to students. 


\section{Acknowledgments}

The authors gratefully acknowledge the support provided by the National Science Foundation through grant EEC 1519467. Any opinions, findings, and conclusions or recommendations expressed in this material are those of the authors and do not necessarily reflect the views of the National Science Foundation.

\section{References:}

[1] M. D. Koretsky, D. Montfort, S. Nolen, M. Bothwell, S. Davis, and J. Sweeney. "Towards a stronger covalent bond: pedagogical change for inclusivity and equity.” Chemical Engineering Education, vol. 52, 2018.

[2] M. D. Koretsky, "Program level curriculum reform at scale: Using studios to flip the classroom.” Chemical Engineering Education, vol. 49, pp. 47-57, 2015.

[3] R. A. Engle, P. D. Nguyen, and A. Mendelson, "The influence of framing on transfer: Initial evidence from a tutoring experiment.” Instructional Science, vol. 39, pp. 603-628, 2011.

[4] J. W. Pellegrino, and M. L. Hilton, Committee on Defining Deeper Learning and 21st Century Skills, Education for Life and Work: Developing Transferable Knowledge and Skills in the 21st Century. Washington, DC: National Research Council of the National Academies, 2011.

[5] M. L. Gick, and K. J. Holyoak, "Schema induction and analogical transfer.” Cognitive psychology, vol. 15, pp. 1-38, 1983.

[6] S. M. Barnett, and S. J. Ceci, "When and where do we apply what we learn?: A taxonomy for far transfer." Psychological bulletin, vol. 128, pp. 612, 2002.

[7] A. Pickering, The mangle of practice: Time, agency, and science. University of Chicago Press, 2010.

[8] B. Barron, D. Schwartz, N. Vye, A. Moore, A. Petrosino, L. Zech, and J. Bransford, "Doing with understanding: Lessons from research on problem-and project-based learning." Journal of the Learning Science, vol. 7, pp. 271-311, 1998.

[9] S. P. Lorona, S. B. Nolen, and M. D. Koretsky, "The Two Worlds of Engineering Student Teams.” Proceedings of the 2018 American Society for Engineering Education Annual Conference \& Exposition. 2018 